10

\title{
Фотодеструкция поливинилпирролидона в водных растворах нитратов металлов
}

\author{
() С.К. Евстропьев ${ }^{1,2,3}$, Н.В. Никоноров ${ }^{2}$, А.С. Саратовский 2 ॠ \\ ${ }^{1}$ Санкт-Петербургский государственный технологический институт (Технический университет), \\ 190013 Санкт-Петербург, Россия \\ 2 Университет ИТМО, \\ 197101 Санкт-Петербург, Россия \\ ${ }^{3}$ НПО „ГОИ им. С.И. Вавилова“, \\ 192171 Санкт-Петербург, Россия \\ ฯ e-mail: saratovskija@inbox.ru
}

Поступила в редакцию 20.03.2020 г.

В окончательной редакции 26.06.2020 г.

Принята к публикации 07.07.2020 г.

\begin{abstract}
Представлены результаты исследования фоторазложения поливинилпирролидона в растворах нитратов металлов. Этот полимер окисляется в нитратных растворах под действием УФ излучения, реагируя с активными формами кислорода и замедляя фоторазложение других органических веществ. УФ облучение наночастиц $\mathrm{ZnO}$, стабилизированных поливинилпирролидоном, приводит к его удалению и росту наночастиц.
\end{abstract}

Ключевые слова: фотоокисление, нитрат, полимер, наночастица, спектр поглощения, раствор.

DOI: $10.21883 /$ OS.2020.11.50179.174-20

\section{Введение}

Растворимые органические полимеры широко используются для стабилизации в растворах различных наночастиц и играют важную роль в формировании структуры и свойств наноматериалов. Поливинилпирролидон (ПВП) часто используется в коллоидно-химических методах синтеза наночастиц, препятствуя их неконтролируемому росту и агрегации [1-8]. Различные наночастицы, стабилизированные ПВП, перспективны в биомедицинских $[1,2,6-8]$ и оптических [3-5] приложениях.

Однако стабилизаторы обычно затрудняют взаимодействие реагентов с частицами катализаторов [9]. Так, применение ПВП для стабилизации фотокаталитических частиц может вести к снижению их активности [10], и разрабатываются различные методы удаления ПВП с поверхности наночастиц [9,11-15]. Однако некоторые химические методы удаления ПВП включают применение агрессивных химических реагентов (например, $\left.\mathrm{H}_{2} \mathrm{O}_{2} / \mathrm{H}_{2} \mathrm{SO}_{4}[12]\right)$. Удаление ПВП выжиганием при высоких температурах происходит при высоких температу$\operatorname{pax}[14,15]$ и может влиять на морфологию каталитических наночастиц [14]. Таким образом, развитие методик удаления ПВП с поверхности наночастиц является актуальной задачей.

Фотохимические процессы широко используются для ускорения разложения различных органических веществ [16-21]. Гибкость фотохимических процессов является их существенным достоинством для удаления заданных количеств органических веществ.

Довольно подробное исследование фотоокисления ПВП в твердой фазе и в водных растворах было приве- дено в [19-21]. Установлены различия в фотоокислении ПВП в растворах и в твердой фазе и идентифицированы образующиеся продукты фотохимических реакций [19]. Однако было установлено, что ПВП обладает высокой фотостойкостью, и фотохимические процессы его разложения протекают медленно [19]. Поэтому для эффективного удаления ПВП требуется интенсификация фотохимических процессов.

Фотоокисление органических полимеров являлось объектом многочисленных исследований, описывающих механизмы фотохимических реакций [17-19,21]. Важная роль химически активных форм кислорода (reactive oxygen species, ROS), которые окисляют полимеры, была отмечена в $[17,18,22]$.

Известно, что добавки нитратов металлов значительно ускоряют фотоокисление органических соединений в жидкостях, увеличивая фотогенерацию ROS [23-26]. Фоторазложение нитрат-анионов сопровождается образованием химически активных форм кислорода $[25,26]$ :

$$
\mathrm{NO}^{3-}+h v=\mathrm{NO}_{2}^{-}+\dot{\mathrm{O}} \text {. }
$$

Образующиеся химически активные формы кислорода быстро окисляют органические соединения. Таким образом, эти данные позволяют предположить, что нитраты могут рассматриваться как эффективные добавки, которые могут ускорить фотохимическое разложение молекул ПВП и их удаление с поверхности наночастиц.

Целью настоящей работы являлось изучение процессов фоторазложения ПВП в водных растворах нитратов металлов. Кроме того, мы исследовали влияние ПВП на фоторазложение органических загрязнений и спектраль- 
Химический состав растворов, использованных для формирования золей $\mathrm{ZnO}$

\begin{tabular}{c|c|c|c|c|c}
\hline \multirow{2}{*}{ Золь } & \multicolumn{5}{|c}{ Химический состав, wt.\% } \\
\cline { 2 - 6 } & $\mathrm{H}_{2} \mathrm{O}$ & Пропанол-2 & $\mathrm{Zn}\left(\mathrm{NO}_{3}\right)_{2}$ & $\mathrm{NH}_{4} \mathrm{OH}(10 \%)$ & ПВП \\
\hline 1 & 34.8 & 60.7 & 0.3 & 0.3 & 3.9 \\
2 & 34.6 & 60.5 & 0.8 & 0.3 & 3.8
\end{tabular}

ные свойства оксидных наночастиц, стабилизированных этим полимером.

\section{1. Методика экспериментов}

\section{1. Материалы}

В работе были исследованы фотохимические процессы в водных растворах высокомолекулярного ПВП $\left(M_{w}=1300000\right.$; Sigma-Aldrich). Водные растворы этого полимера были изготовлены растворением заданных количеств ПВП в дистиллированной воде при непрерывном перемешивании в течение $1 \mathrm{~h}$ при комнатной температуре. Для изучения влияния нитратов на фотоокисление ПВП часть этих растворов смешивалась с раствором нитрата цинка (ОАО „Реактив“, Россия) при перемешивании в течение $30 \mathrm{~min}$ при комнатной температуре. Полученные смешанные растворы были однородными и прозрачными.

Растворы ПВП, содержащие нитрат цинка, были использованы для формирования наночастиц $\mathrm{ZnO}$ путем медленного добавления при интенсивном перемешивании разбавленного раствора гидроксида аммония. Химический состав растворов, использованных для формирования золей $\mathrm{ZnO}$, приведен в таблице.

\section{2. Спектральные свойства}

Спектры поглощения были измерены в диапазоне длин волн 200-800 nm при использовании спектрофотометра Shimadsu UV-3600. Кварцевые кюветы толщиной $1 \mathrm{~cm}$ были использованы для этих измерений и для УФ облучения растворов.

ИК спектры растворов были измерены с использованием спектрофотометра Bruker ALPHA. Анализ пиков поглощения в ИК спектрах был основан на данных $[19,21]$.

\section{3. УФ облучение}

Для фоторазложения ПВП в [19,21] применялись различные источники света. В [19] использовался источник света с $\lambda_{e m} \geq 300 \mathrm{~nm}$. Ртутная лампа, излучающая в более коротковолновом спектральном диапазоне, была использована для разложения ПВП в [21].
Нитрат-анионы $\mathrm{NO}_{3}^{-}$имеют интенсивные полосы поглощения в УФ диапазоне 200 и $305 \mathrm{~nm}$ [26]. Нитританионы $\mathrm{NO}_{2}^{-}$, образующиеся на первой стадии фоторазложения анионов $\mathrm{NO}_{3}^{-}$и принимающие участие в последующих стадиях фотохимических процессов, также имеют полосы поглощения в УФ диапазоне $(\lambda=205$ и $36 \mathrm{~nm}$ ) [26]. Поэтому в настоящей работе УФ облучение выполнялось при использовании ртутной лампы высокого давления, излучающей свет в широком спектральном диапазоне $(200-580 \mathrm{~nm})$. Плотность мощности излучения составляла $0.25 \mathrm{~W} / \mathrm{cm}^{2}$.

\section{4. Исследование фотоокисления ПВП при использовании органического красителя}

Для исследования кинетики фотоокисления ПВП в нитратных растворах использовался косвенный метод, состоящий в изучении фоторазложения индикаторного органического красителя, который был добавлен в раствор ПВП. Использованный нами подход был основан на том, что образующиеся под действием УФ излучения ROS очень химически активны и окисляют оба органических соединения (ПВП и органический краситель):

$$
\begin{aligned}
& \text { ROS }+ \text { PVP } \rightarrow \text { Product I, } \\
& \text { ROS }+ \text { Dye } \rightarrow \text { Product II. }
\end{aligned}
$$

В присутствии в растворе нескольких органических соединений процессы их взаимодействия с химически активными формами кислорода являются конкурентными, и это снижает скорость фоторазложения каждого из этих органических соединений, что определяется следующими факторами:

1) поглощением света другими органическими молекулами, и

2) расходом ROS на окисление всех органических соединений. Это определяет уменьшение доли химического кислорода, реагирующего с каждым из них.

ПВП характеризуется относительно высокой прозрачностью в видимом и ближнем УФ спектральных диапазонах по сравнению с большинством органических. Таким образом, поглощение ПВП мало, и наблюдаемое изменение скорости разложения красителя указывает на конкурирующий фотохимический процесс разложения ПВП.

Концентрация ROS в растворе очень мала по сравнению с концентрациями ПВП и органического красителя, и кинетика процессов (2) и (3) определяется скоростью фоторазложения нитрат-анионов по реакции (1). Химические реакции (2) и (3) являются конкурирующими, и изменение скорости окисления красителя позволяет оценить скорость окисления ПВП.

Диазокраситель Chicago Sky Blue B (CSB) (Sigma Aldrich) был использован нами в качестве модельного органического загрязнения для исследования кинетики фоторазложения ПВП. Этот краситель использовался в [27-30] для исследования фотокаталитических свойств 


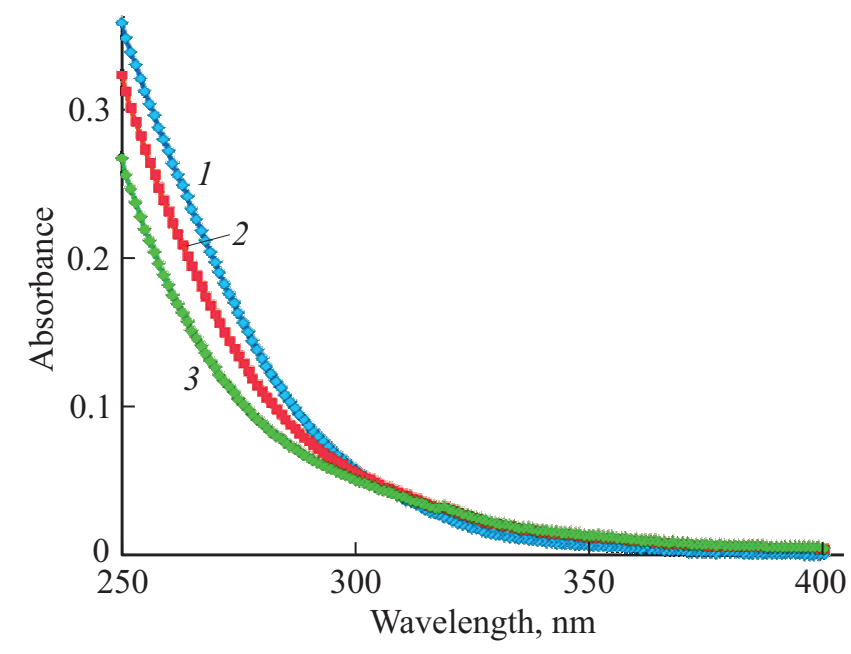

Рис. 1. Влияние УФ облучения в течение 0 (кривая 1), 1 (кривая 2), $3 \min$ (кривая 3) на спектр поглощения раствора ПВП $\left(3.8 \cdot 10^{-5} \mathrm{M}\right)$.

различных материалов. Структура и спектральные свойства этого красителя были детально описаны в [31]. Раствор CSB был изготовлен растворением порошка красителя в дистиллированной воде.

\section{2. Экспериментальные результаты и обсуждения}

\section{1. Фотоокисление ПВП в водных растворах под действием УФ излучения}

Рис. 1 демонстрирует влияние УФ облучения на спектр поглощения водного раствора ПВП. Исходный раствор ПВП характеризуется высокой прозрачностью в ближней УФ и видимой частях спектра (кривая 1), что согласуется с ранее опубликованными результатами [32]. УФ облучение водных растворов приводит к быстрому окислению молекул полимера и изменению спектральных свойств этих растворов в УФ диапазоне (рис. 1). Существенное уменьшение поглощения наблюдается в диапазоне $\lambda=250-300 \mathrm{~nm}$, и небольшое увеличение поглощения при $\lambda>300 \mathrm{~nm}$ наблюдаются в спектрах растворов после их УФ облучения.

Рис. 2 иллюстрирует некоторые изменения в ИК спектрах растворов ПВП после их УФ облучения. Влияние УФ облучения на форму ИК спектра раствора ПВП, не содержащего нитрат-анионов, незначительно. Добавка нитрата цинка в раствор ПВП приводит к росту полосы поглощения при $\sim 1380 \mathrm{~cm}^{-1}$, что связано с анионами $\mathrm{NO}_{3}^{-}[33,34]$. Вставка на рис. 2 показывает детали изменения в спектрах растворов ПВП в интервале $1280-1480 \mathrm{~cm}^{-1}$. Интенсивность пиков поглощения в спектрах уменьшается при УФ облучении, и пики становятся более слабыми (вставка на рис. 2). Характер спектральных изменений в диапазоне $1280-1480 \mathrm{~cm}^{-1}$ аналогичен данным, приведенным в [21].
Рис. 2 показывает, что уменьшаются интенсивности пиков при 1470 и $1420 \mathrm{~cm}^{-1}$, которые связаны, по данным [19], с колебаниями групп $\mathrm{CH}_{2}$ в различных частях молекулы ПВП. Это может свидетельствовать об обрыве части углеводородных цепей полимера. Сравнение кривых 2 и 3 (рис. 2) показывает, что это явление более отчетливо проявляется в растворе ПВП, содержащем $\mathrm{Zn}\left(\mathrm{NO}_{3}\right)_{2}$, и определяется более интенсивной фотостимулированной генерацией ROS.

Сопоставление кривых 1 и 2 (рис. 2) показывает, что интенсивность пика при $1285-1291 \mathrm{~cm}^{-1}$, который связан с колебаниями $\mathrm{C}-\mathrm{N}-$ связи в молекулах ПВП $[19,21]$, не изменяется в растворе, не содержащем добавки нитрата. Уменьшение интенсивности этого пика наблюдается в спектре раствора ПВП, содержащего добавки нитрата цинка, что свидетельствует о заметных изменениях в структуре полимера.

Необходимо отметить, что эти изменения в ИК спектрах наблюдаются после облучения растворов ПВП в течение $10 \mathrm{~min}$. Быстрое разложение ПВП под действием УФ излучения было описано ранее [21]. В отличие от этого фоторазложение ПВП под действием более длинноволнового излучения $(\lambda>300 \mathrm{~nm})$ было медленным и заметные результаты этого фотохимического процесса наблюдались только после облучения в течение сотен часов [19]. Это явление может быть связано со слабым поглощением света при $\lambda>300 \mathrm{~nm}$ молекулами (рис. 1).

На основании полученных экспериментальных данных и результатов $[19,21]$ мы можем придти к заключению, что именно УФ облучение стимулирует быстрое окисление ПВП в водных растворах, и добавка нитратов

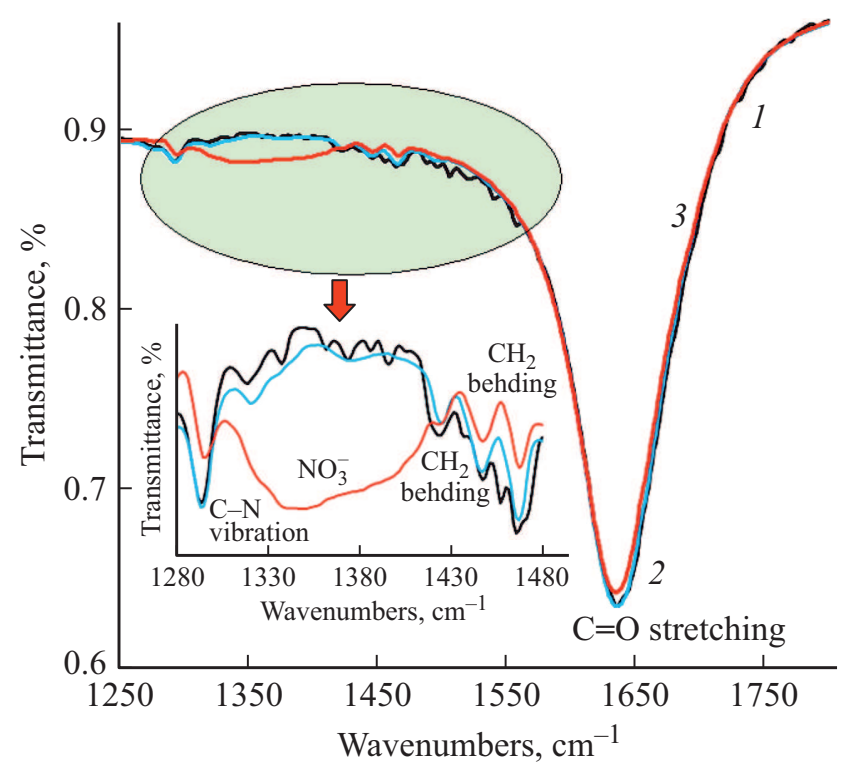

Рис. 2. ИК спектры исходного водного раствора ПВП $\left(1 \cdot 10^{-6} \mathrm{M}\right)$ (кривая 1); его же после УФ облучения в течение $10 \mathrm{~min}$ (кривая 2); водного раствора ПВП $\left(1 \cdot 10^{-6} \mathrm{M}\right)$, содержащего $\mathrm{Zn}\left(\mathrm{NO}_{3}\right)_{2}\left(1 \cdot 10^{-3} \mathrm{M}\right)$ после УФ облучения в течение $10 \min$ (кривая 3). 
дополнительно существенно ускоряет этот фотохимический процесс.

\section{Фотоокисление ПВП}

Рис. 3 демонстрирует изменения спектров поглощения растворов красителя при УФ облучении раствора, содержащего краситель и $\mathrm{Zn}(\mathrm{NO})_{2}(a)$ и аналогичного раствора, содержащего кроме этих компонентов и добавку ПВП $(b)$. Широкая и интенсивная полоса поглощения красителя наблюдается в области 615-650 nm в спектрах обоих растворов. Уменьшение интенсивности этой полосы поглощения указывает на фоторазложение красителя и позволяет оценить изменение концентрации красителя при воздействии света.

Рис. 4 иллюстрирует влияние ПВП на изменение окраски растворов красителя после УФ облучения в течение $5 \mathrm{~min}$. Раствор без ПВП обесцвечивается быстро (рис. $4, b)$, в то время как окраска раствора с добавкой ПВП практически не изменяется (рис. 4, $a$ ).

Кинетика фоторазложения органических соединений часто описывается экспоненциальной функцией как фо-
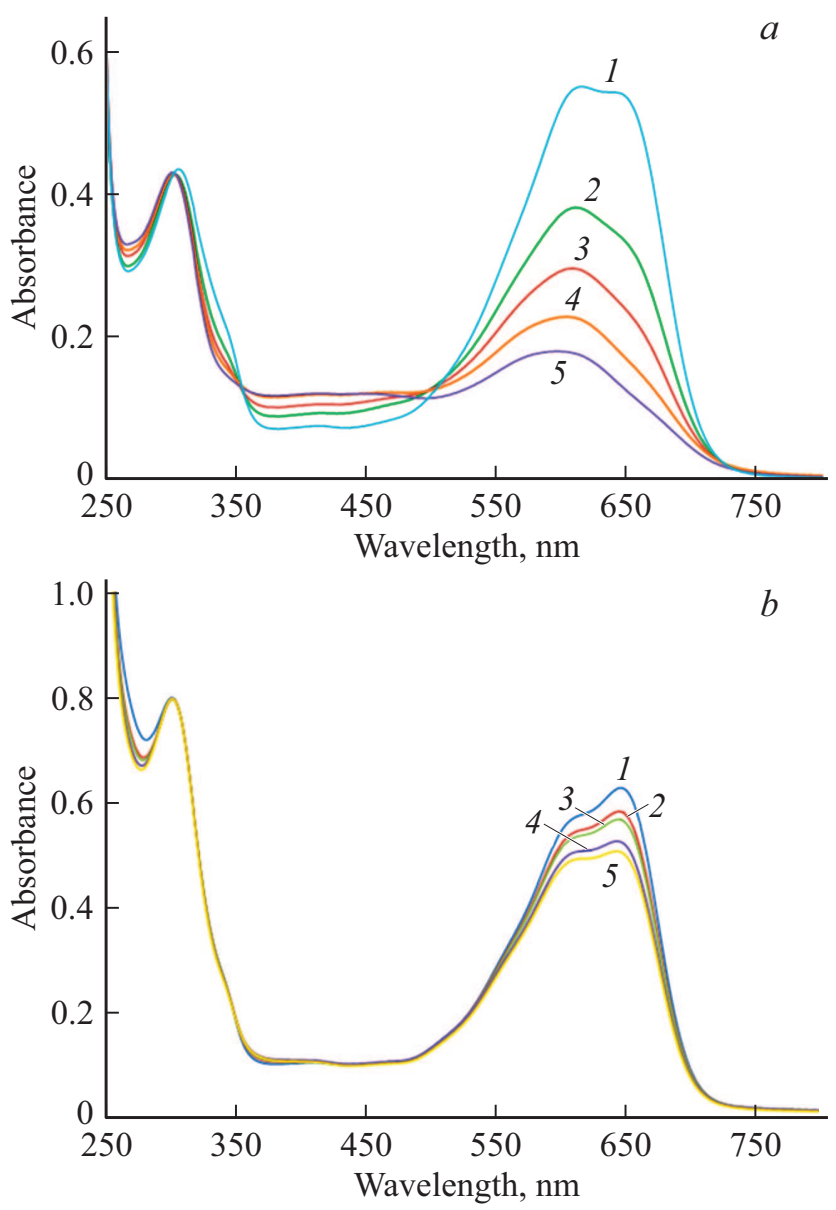

Рис. 3. Изменения спектров поглощения растворов красителя $\left(1 \cdot 10^{-6} \mathrm{M}\right)$, содержащих $\mathrm{Zn}\left(\mathrm{NO}_{3}\right)_{2}\left(3 \cdot 10^{-3} \mathrm{M}\right)$ (a) и $\mathrm{Zn}\left(\mathrm{NO}_{3}\right)_{2}\left(3 \cdot 10^{-3} \mathrm{M}\right)$ и $\mathrm{PVP}\left(2.8 \cdot 10^{-6} \mathrm{M}\right)$ (b) при УФ облучении в течение: 0 (1), 2 (2), 3.5 (3), 5 (4), $6.5 \mathrm{~min}$ (5).

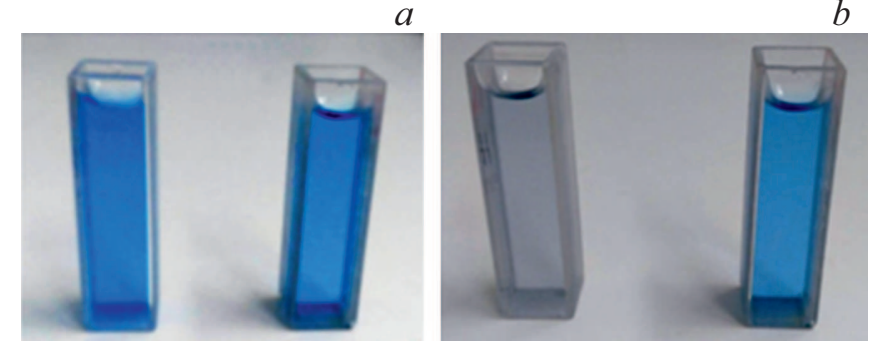

Рис. 4. Влияние ПВП на окраску растворов красителя после УФ облучения. Растворы красителя до облучения - правые кюветы на фото; растворы после облучения в течение 5 min левые кюветы. Растворы без ПВП $(a)$, растворы с добавкой ПВП $(b)$.

тохимическая реакция первого порядка $[35,36]$ :

$$
\frac{C}{C_{0}}=e^{-k t},
$$

где $C_{0}$ и $C-$ начальная и текущая концентрации органического вещества, $t$ - продолжительность светового облучения и $k-$ константа скорости фотохимической реакции.

Рис. 5 показывает изменение относительной концентрации ПВП в растворе в процессе УФ облучения. Эта зависимость была построена на основе экспериментальных данных, приведенных на рис. 3, $a, b$. Видно, зависимость описывается экспоненциальной функцией с константой скорости $k=0.032 \mathrm{~min}^{-1}$.

На основании полученных экспериментальных данных мы можем придти к заключению о том, что фотоокисление ПВП быстро протекает в водных растворах, содержащих добавки нитрата цинка. В рассмотренных фотохимических процессах ПВП реагирует с ROS, уменьшая скорость фоторазложения других органических веществ.

\section{2. Фоторазложение ПВП на поверхности наночастиц ZnO}

Рис. 5 демонстрирует влияние УФ облучения на спектр поглощения золя 1. Этот золь был изготовлен, используя добавку малого количества аммиачной воды, и содержание в нем $\mathrm{ZnO}$ мало. Прозрачность этого золя в видимом спектральном диапазоне высока и практически не изменяется при УФ облучении.

УФ облучение золей сдвигает край поглощения в длинноволновую часть спектра (рис. 6). Это явление объясняется фотоокислением молекул ПВП и последующим ростом частиц $\mathrm{ZnO}$.

Уравнение Тауца [37] использовалось для определения значений ширины запрещенной зоны наночастиц $\mathrm{ZnO}$. Для прямозонных полупроводников это уравнение может быть записано в виде

$$
(\alpha h v)^{2}=A\left(h v-E_{g}\right),
$$

где $h v-$ энергия фотона, $E_{g}$ - ширина запрещенной зоны, $A-$ постоянная, $\alpha-$ коэффициент поглощения. 


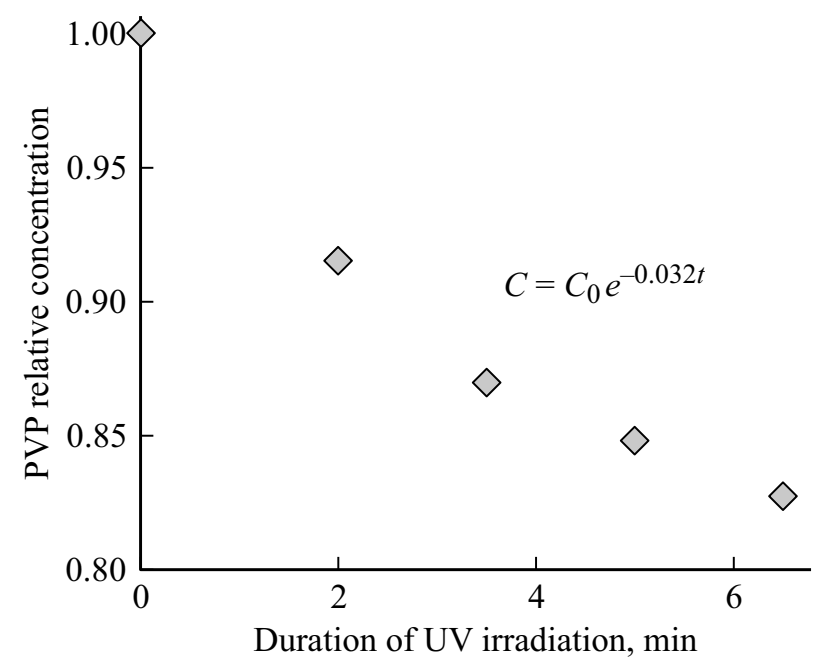

Рис. 5. Кинетика разложения ПВП в процессе УФ облучения.

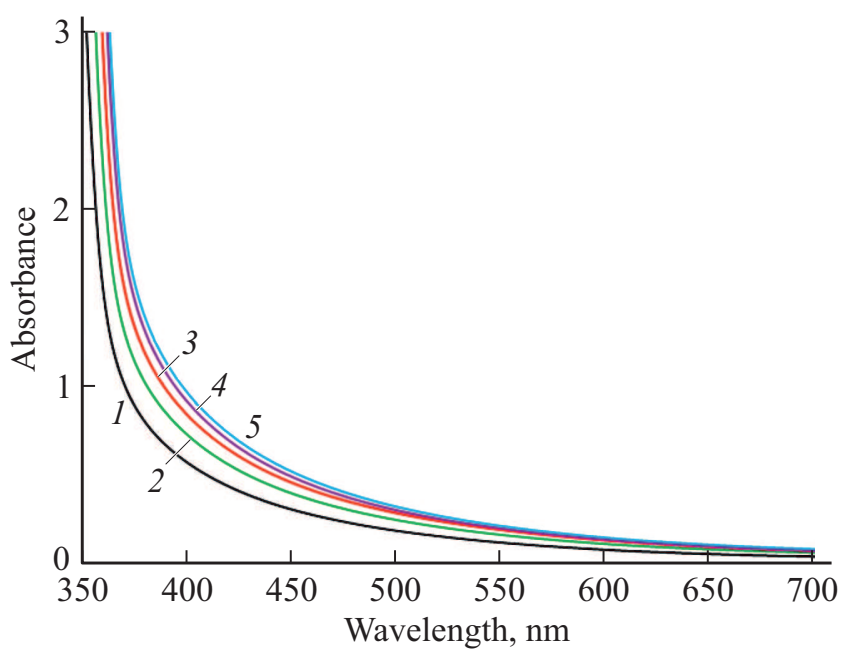

Рис. 6. Влияние УФ облучения на спектр поглощения золя $1 \mathrm{c}$ низкой концентрацией ионов цинка (таблица). Продолжительность УФ облучения: 0 (исходный золь, кривая 1), 2 (2), 5 (3), $10(4), 15 \min (5)$

Построение графиков в координатах $(\alpha h v)^{2}=f(h v)$ использовалось для определения значений $E_{g}$ (рис. 7, $a$ ).

Полученные значения ширины запрещенной зоны выше значения $E_{g}$ макроскопических кристаллов $\mathrm{ZnO}$ $(3.3 \mathrm{eV}$ [38]). Это явление определяется квантоворазмерным эффектом и связано с малым размером нанокристаллов $\mathrm{ZnO}$, формирующихся в присутствии ПВП. Данные, представленные на рис. 7, $b$, показывают, что фотостимулированное окисление молекул ПВП ведет к росту наночастиц $\mathrm{ZnO}$ и соответствующему уменьшению ширины запрещенной зоны. Значение ширины запрещенной зоны $\mathrm{ZnO}$ наночастиц значительно уменьшается при УФ облучении и приближается к значению $E_{g}$ макроскопических кристаллов.

Увеличение содержания $\mathrm{Zn}\left(\mathrm{NO}_{3}\right)_{2}$ в исходной жидкой смеси (золь 2; таблица) приводит к увеличению коли- чества частиц $\mathrm{ZnO}$ и соответствующему значительному росту поглощения света в УФ диапазоне (рис. 8). Полоса поглощения при $300 \mathrm{~nm}$, которая наблюдается в спектре свежеприготовленного золя 2 (кривая 1, рис. 8), позволяет предположить переналожение в спектре полосы поглощения нитрат анионов и экситонной полосы поглощения наночастиц $\mathrm{ZnO}$. УФ облучение в течение $10 \mathrm{~min}$ сдвигает эту полосу до $\lambda \sim 345 \mathrm{~nm}$, что определяется ростом наночастиц $\mathrm{ZnO}$, связанным с окислением части молекул ПВП.

Размер нанокристаллов $\mathrm{ZnO}$ в изготовленных раствоpax был оценен, используя положение в спектре максимума экситонной полосы поглощения по уравнению, приведенному в [39]:

$$
r(\mathrm{~nm})=\frac{-0.3049+\sqrt{-26.23+10240.72 / \lambda_{\max }}}{-6.3829+2483.2 / \lambda_{\max }},
$$
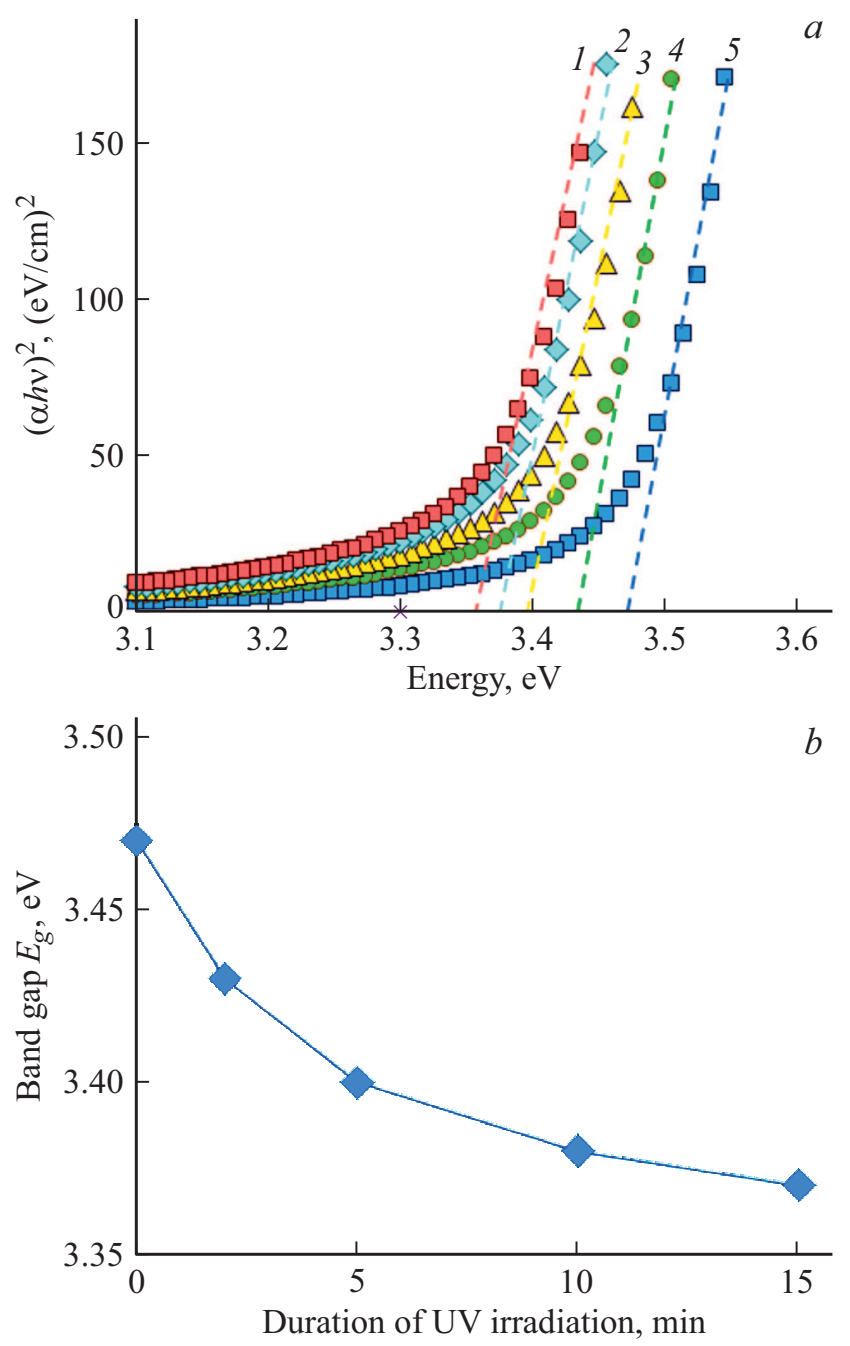

Рис. 7. (a) Графики $(\alpha h v)^{2}=f(h v)$ для $\mathrm{ZnO}$ золя 1 , подвергнутого УФ облучению в течение: 0 (исходный золь, кривая 1 ), 2 (2), 5 (3), 10 (4), $15 \mathrm{~min}(5) ;(b)$ Зависимость ширины запрещенной зоны $E_{g}$ наночастиц $\mathrm{ZnO}$ от продолжительности УФ облучения. 


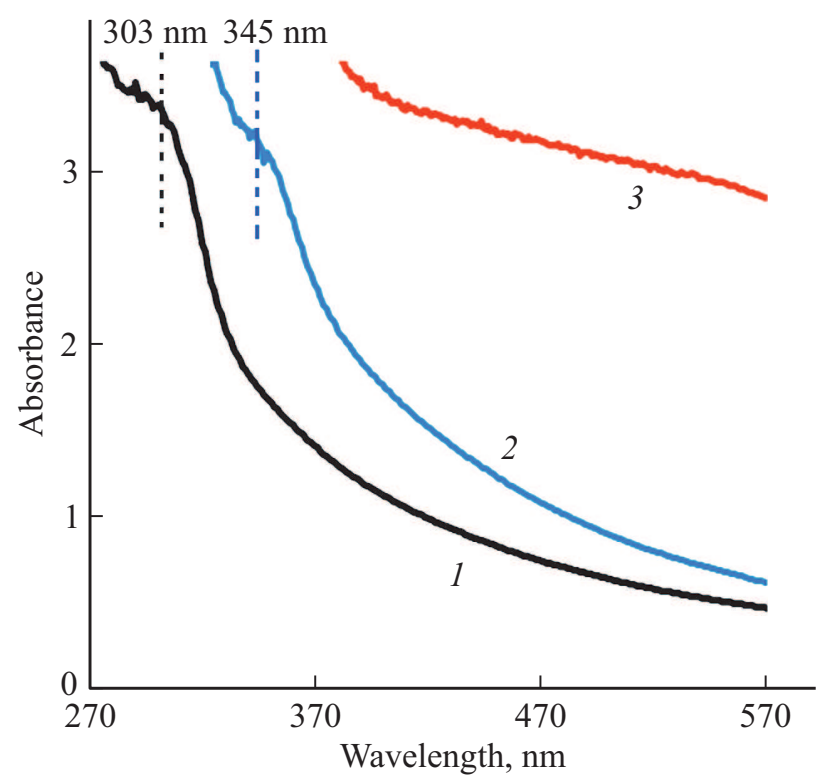

Рис. 8. Влияние УФ облучения на спектр поглощения $\mathrm{ZnO}$ золя 2 с высокой концентрацией ионов цинка (таблица). Продолжительность УФ облучения: 0 (исходный золь, кривая 1), $10 \tilde{(2)}, 15 \min (3)$.

где $\lambda_{\max }$ - длина волны пика поглощения в $\mathrm{nm}$. Расчеты показали, что размер частиц $\mathrm{ZnO}$ увеличивается с 1.3 до $1.9 \mathrm{~nm}$ после УФ облучения в течение $10 \mathrm{~min}$.

Увеличение продолжительности облучения до $15 \mathrm{~min}$ приводит к помутнению раствора (кривая 3, рис. 8), что определяется разложением дополнительной части молекул ПВП, ростом и агрегацией частиц $\mathrm{ZnO}$.

\section{Заключение}

Поливинилпирролидон быстро окисляется под действием УФ излучения в водных растворах нитратов, взаимодействуя с образующимися активными формами кислорода и уменьшая скорость фоторазложения других органических соединений, присутствующих в растворах. УФ облучение золей $\mathrm{ZnO} /$ ПВП ослабляет стабилизирующий эффект молекул ПВП, что приводит к росту частиц $\mathrm{ZnO}$ и соответствующему уменьшению ширины запрещенной зоны. УФ облучение наночастиц, покрытых молекулами ПВП, является эффективным путем удаления этого полимера с их поверхности.

\section{Благодарности}

Работа была частично (Евстропьев С.К.) поддержана Российским научным фондом (грант № 19-19-00596).

\section{Конфликт интересов}

Авторы заявляют, что у них нет конфликта интересов.

\section{Список литературы}

[1] Liu H., Zhang B., Shi H., Tang Y., Jiao K., Fu X. // J. Mater. Chem. 2008. V. 18. P. 2573-2580.

[2] Kockur K.M., Mourdikoudis S., Polavarapu L., Skrabalak S.E. // Dalton Transactions. 2015. V. 44. № 41. P. 17883 17905.

[3] Evstropiev S.K., Kislyakov I.M., Bagrov I.V., Belousova I.M. // Polym. Adv. Technol. 2016. V. 27. P. 314-317. doi 10.1002/pat.3642.

[4] Lin Guo, Shihe Yang, Chulei Yang, Ping Yu, Jiannong Wang, Weikun Ge, Wong G.K.L. // Appl. Phys. Lett. 2000. V. 76. № 20. P. 2901-2903.

[5] Кулагина А.С., Евстропьев С.К., Розанов Н.Н., Власов B.B. // ФТП. 2018. Т. 52. В. 8. С. 865-871; Kulagina A.S., Evstrop'ev S.K., Rosanov N.N., Vlasov V.V. // Semiconductors. 2018. V. 52. № 8. P. 997-1003.

[6] Евстропьев К.С., Гатчин Ю.А., Евстропьев С.К., Дукельский К.В., Кисляков И.М., Пегасова Н.А., Багров И.В. // Опт. и спектр. 2016. Т. 120. № 3. С. 434 441.; Evstrop'ev K.S., Gatchin Yu.A., Evstrop'ev S.K., Dukels'kii K.V., Kislyakov I.M., Pegasova N.A., Bagrov I.V. // Opt. Spectr. 2016, V. 120. № 3. P. 415-422. doi 10.7868/S0030403416030065.

[7] Hariharan R., Siganthi A., Sethilkumar S., Rajarajan M. // J. Photochem. Photobiol. A Chem. 2013. V. 252. P. 107-115.

[8] Evstropiev S.K., Dukelskii K.V., Karavaeva A.V., Vasilyev V.N., Kolobkova E.V., Nikonorov N.V., Evstropyev K.S. // J. Mater. Sci.: Mater. Med. 2017. V. 28. № 7. Article 102. doi 10.1007/s10856-017-5909-4.

[9] Niu Z., Li Y. // Chem. Mater. 2014. V. 26. № 1. P. 72-83.

[10] Sudha M., Rajarajan M. // IOSR J. Appl. Chem. 2013. V. 3. N 3. P. 45-53.

[11] Nguyen Viet Long, M. Ohaki, M. Nogami, Tong Duy Hien // Colloid Polym. Sci. 2011. V. 289. № 12. P. 1373-1386.

[12] Monzó J., Koper M.T.M., Rodriguez P. // Chem. Phys. Chem. 2012. V. 13. № 3. P. 709-715.

[13] Muhua Luo, Yuanchen Hong, Weifeng Yao, Cunping Huang, Qunjie Xu, Qiang $W u$ // J. Mater. Chem. 2015. V. 3. № 6. P. 2770-2775.

[14] Long N.V., Ohtaki M., Nogami M., Hien T.D. // Colloid Polymer Sci. 2011. V. 89. № 12. P. 1373-1386.

[15] Du Y., Yang P., Mou Z.G., Hua N.P., Jiang L. // J. Appl. Polym. Sci. 2006. V. 99. № 61. P. 23-26. doi 10.1002/app.21886.

[16] Horikoshi S., Serpone N., Hisamatsu Y., Hidaka H.H. // Environmental Sci. Technol., 1998. V. 32. № 24. P. 4010 4016. doi 10.1021/es9710464.

[17] Yousif E., Haddad R. // SpringerPlus. 2013. V. 2. P. 398.

[18] Larch?é J.-F., Bussiére P.-O., Thérias S., Gardette J.-L. // Polymer Degradation and Stability. 2012. V. 97. № 1. P. 2534.

[19] Hassouna F., Therias S., Mailhot G., Gardette J.-L. // Polymer Degradation and Stability. 2009. V. 94. P. 2257-2266.

[20] Louie S.M., Gorham J.M., Tan J., Hackley V.A. // Enviromnental Sci.: Nano. 2017. V. 4. P. 1866-1875.

[21] Xingfeng Zhu, Ping Lu, Wei Chen, Jian Dong // Polymer. 2010. V. 51. P. 3054-3063.

[22] Lipovsky B., Tzitrinovich Z., Friedmann H., Applerot G., Gedanken A., Lubart R. // J. Phys. Chem. C. 2009. V. 36. P. $15997-16001$.

[23] Hu W., Wu F., Liu W., Liu J. // J. Adv. Oxidation Technol. 2018. V. 21. № 1. Article ID-20170110. 
[24] Calza P., Vione D., Novelli A., Pelietti E., Minero C. // Sci. Total Environ. 2012. V. 439. P. 67-75.

[25] Warneck P., Wurzinger C. // J. Phys. Chem. 1988. V. 92. № 22. P. 6278-6283.

[26] Mark J., Bolton J.R. // J. Photochem. Photobiol. A: Chemistry. 1999. V. 128. P. 1-13.

[27] Zulkarnain Zainal, Lee Kong Hui, Mohd Zobir Hussein, Yun Hin Taufiq-Yap, Abdul Halim Abdullah, Irmati Ramli // J. Hazard. Mater. B. 2005. V. 125. P. 113-120.

[28] El-Bahy Z.M., Ismail A.A., Mohamed R.M. // J. Hazard. Mater. 2009. V. 166. № 1. P. 138-143.

[29] Boltenkov I.S., Kolobkova E.V., Evstropiev S.K. // J. Photochem. Photobiol. A: Chemistry. 2018. V. 367. P. 458464. doi 10.106/j.photochem.2018.09.016.

[30] Волкова Н.А., Евстропьев С.К., Истомина О.В., Колобкова Е.В. // Опт. и спектр. 2018. Т. 124. В. 4. C. 472-476; Volkova N.A., Evstropiev S.K., Istomina O.V., Kolobkova E.V. // Opt. Spectr. 2018. V. 124. № 4. P. 489-493.

[31] Abbott L.C., Batchelor S.N., Oakes J., Lindsay Smith J.R., Moore J.N. // J. Phys. Chem. B. 2004. V. 108. P. 13786-13735.

[32] Vempati S., Ertas Y., Uyar T. // J. Phys. Chem. C. 2013. V. 117. P. 21609-21618.

[33] Miller F.A., Wilkins C.H. // Analytic Chem. 1952. V. 24. № 8. P. 1253-1294.

[34] Goebbert D.J., Garand E., Wende T., Bergmann R., Meijer G., Asmis K.R., Newmark D.M. // J. Phys. Chem. 2009. V. 113. P. 7584-7592.

[35] Majeed I.A., Murray W.J., Newton D.W., Othman S., ATurk W.A. // J. Pharm. Pharmacol. 1987. V. 39. № 12. P. 1044 1046.

[36] Venkata V.V., Sadashivaiah P.H. // Europ. J. Chem. 2012. V. 3. № 2. P. 191-195.

[37] Tauc J. // Mater. Res. Bull. 1968. V. 3. P. 37-46.

[38] Ohtomo A., Kawasaki M., Koida T., Masubuchi K., Koinuma H., Sakurai Y., Yoshida Y., Yasuda T., Segawa Y. // Appl. Phys. Lett. 1998. V. 72. P. 2466.

[39] Talam S., Karumuri S.R., Gunnam N. // ISRN Nanotehnology. 2012 (2012) Article ID 372505, 6 pages. doi $10.5402 / 2012 / 372505$. 